\title{
Altered myocardial perfusion during dobutamine stress testing in silent versus symptomatic myocardial ischaemia assessed by quantitative MIBI SPET imaging
}

\author{
Abdou Elhendy ${ }^{1}$, Marcel L. Geleijnse ${ }^{1}$, Jos R.T.C. Roelandt ${ }^{1}$, Jan H. Cornel${ }^{1}$, Ron T. van Domburg ${ }^{1}$, \\ Ambroos E.M. Reijs², Peter R. Nierop1, Paolo M. Fioretti1, 2 \\ 1 Thoraxcenter, University Hospital Rotterdam-Dijkzigt, Rotterdam, The Netherlands \\ 2 Department of Nuclear Medicine, University Hospital Rotterdam-Dijkzigt, Rotterdam, The Netherlands
}

Received 3 January and in revised from 3 April 1996

\begin{abstract}
The aim of the study was to compare the extent and severity of reversible underperfusion in silent versus painful myocardial ischaemia during the dobutamine stress test. A consecutive series of 85 patients with significant coronary artery disease and reversible perfusion defects on technetium- $99 \mathrm{~m}$ methoxyisobutylisonitrile single-photon emission tomography performed at rest and during high-dose dobutamine stress (up to $40 \mu \mathrm{g}$ $\mathrm{kg}^{-1} \mathrm{~min}^{-1}$ ) were studied. The left ventricle was divided into six segments. An ischaemic perfusion score was derived quantitatively by subtracting the rest from the stress defect score. Patients with multivessel disease had a higher ischaemic score $(610 \pm 762$ vs $310 \pm 411, P<0.05)$ and a higher number of reversible perfusion defects $(2.1 \pm 1.2$ vs $1.1 \pm 0.8, P<0.01)$ than patients with singlevessel disease. Typical angina occurred in 37 patients (44\%) during the test. There was no significant difference between patients with and patients without angina with respect to age, gender, peak rate-pressure product, prevalence of previous myocardial infarction, diabetes mellitus, multivessel disease or number of stenotic coronary arteries. Stress, rest and ischaemic scores as well as the number and distribution of reversible defects were not different in patients with and patients without angina. Patients with angina more frequently had a history of typical angina before the test $(43 \%$ vs $17 \%, P<0.01)$ and ST-segment depression during the test $(54 \%$ vs $25 \%$, $P<0.01)$. It is concluded that in patients with coronary artery disease and ischaemia detected by dobutamine scintigraphy, the extent and severity of coronary artery disease and myocardial perfusion abnormalities are similar with or without angina during stress testing.
\end{abstract}

Key words: Silent ischaemia - Dobutamine stress test Methoxyisobutylisonitrile single-photon emission tomography

Correspondence to: P.M. Fioretti, Thoraxcenter, Ba 300, Dr Molewaterplein 40, 3015 GD Rotterdam, The Netherlands
Eur J Nucl Med (1996) 23:1354-1360

\section{Introduction}

Pharmacological stress testing with dobutamine is increasingly used for non-invasive diagnosis and evaluation of coronary artery disease in patients with suspected myocardial ischaemia and inadequate exercise capacity [1-8]. The induction of myocardial ischaemia with dobutamine infusion is mainly due to an increase in myocardial contractility and heart rate [9]. Dobutamine has also been reported to induce coronary blood flow heterogeneity [10]. Recent studies have shown that dobutamine stress testing in conjunction with technetium- $99 \mathrm{~m}$ methoxyisobutylisonitrile (MIBI) or thallium-201 singlephoton emission tomographic (SPET) imaging is an accurate method for the diagnosis and localization of myocardial ischaemia and coronary artery disease based on the detection of reversible underperfusion [3-8]. The latter was shown to be more sensitive than angina and STsegment depression [3-8]. However, the extent and severity of dobutamine-induced underperfusion have not been compared in the presence or absence of concomitant angina. Since recent studies have shown that the extent and severity of exercise-induced underperfusion have an impact on the prognosis $[11,12]$, identification of stress test variables associated with more severe perfusion abnormalities is a clinically relevant issue. Therefore, the aim of this study was to assess the extent and severity of dobutamine-induced perfusion abnormalities with or without angina during dobutamine stress testing in patients with coronary artery disease.

\section{Materials and methods}

Patient population. The study population was derived from a consecutive series of patients with limited exercise capacity referred to the nuclear imaging laboratory of our centre for diagnostic 
evaluation of myocardial ischaemia. All patients underwent dobutamine stress testing in conjunction with 99mTc-MIBI SPET. Eighty-five patients were included according to the following criteria: (1) significant coronary artery disease defined as $\geq 50 \%$ diameter stenosis of $\geq 1$ major epicardial artery; (2) the occurrence of myocardial ischaemia during the test, defined as reversible perfusion defects on MIBI SPET in the distribution of $\geq 1$ stenotic coronary artery; (3) absence of left ventricular hypertrophy or left bundle branch block. Mean age was $60 \pm 10$ years; 61 patients (72\%) were males. A history and/or electrocardiographic evidence of a previous myocardial infarction were present in 47 patients $(55 \%)$. A history of typical effort angina before the test was obtained in 24 patients (28\%). On the day of the test, 65 patients (76\%) were receiving anti-anginal medication, including beta blocker therapy in 44 cases $(52 \%)$.

The patients were selected from among 125 patients with significant coronary artery disease with or without ischaemia on dobutamine MIBI study. Thus, the prevalence of a positive dobutamine MIBI study was $68 \%$ in our series of patients. Among the 40 patients with significant coronary artery disease and without ischaemia detected by dobutamine MIBI SPET, angina occurred in 14 $(35 \%)$ during the test.

Dobutamine stress test. Dobutamine was infused through an antecubital vein starting at a dose of $5 \mu \mathrm{g} \mathrm{kg}^{-1} \mathrm{~min}^{-1}$ for $3 \mathrm{~min}$, then at $10 \mu \mathrm{g} \mathrm{kg}^{-1} \mathrm{~min}^{-1}$ for $3 \mathrm{~min}$, and increasing by $10 \mu \mathrm{g} \mathrm{kg}^{-1} \mathrm{~min}^{-1}$ every 3 min to a maximum of $40 \mu \mathrm{g} \mathrm{kg}^{-1} \mathrm{~min}^{-1}$. Atropine (up to $1 \mathrm{mg}$ ) was given in patients not achieving $85 \%$ of their age-predicted maximal heart rate [5]. The electrocardiogram was monitored throughout dobutamine infusion and recorded each minute. Cuff blood pressure was measured every $3 \mathrm{~min}$. Significant STsegment depression was defined as $\geq 1 \mathrm{~mm}$ horizontal or downsloping depression $80 \mathrm{~ms}$ after the J point, below the resting baseline level. The test was interrupted if severe chest pain, ST-segment depression $>2 \mathrm{~mm}$, ST-segment elevation $>2 \mathrm{~mm}$ in patients without previous myocardial infarction [13], significant ventricular or supraventricular tachyarrhythmia or a fall in systolic blood pressure of $>40 \mathrm{mmHg}$ occurred during the test.

MIBI SPET imaging. Approximately $1 \mathrm{~min}$ before the termination of the stress test, an intravenous dose of $370 \mathrm{MBq}$ of MIBI was administered. The acquisition of stress SPET images was started $1 \mathrm{~h}$ after MIBI injection. For the resting MIBI studies, $370 \mathrm{MBq}$ was injected at least $24 \mathrm{~h}$ after the first study. Image acquisition and interpretation were performed according to a previously described protocol [5]. The left ventricular images were divided into six segments: anterior, septal (subdivided into the anterior and posterior septum), lateral, inferoposterior and apical. A persistent perfusion defect on both stress and rest imaging was classified as a fixed defect. A reversible defect was defined as a perfusion defect on stress images that partially or completely resolved at rest imaging. This was considered diagnostic of ischaemia. An experienced observer, unaware of patients' clinical and angiographic data, reviewed the images. The interpretation was semiquantitatively performed by visual analysis assisted by circumferential profile analysis. Each of the six left ventricular segments was scored on a four-grade classification where $0=$ normal and $3=$ severely reduced or absent uptake. The visual perfusion defect score was derived by the summation of the score of the six myocardial segments for both rest and stress imaging. The difference between the stress and rest scores (ischaemic score) was considered representative of the total amount of stress-induced underperfusion. The perfusion defect score was quantitatively calculated at rest and at stress imaging by measuring the area between the lower limit of normal values $( \pm 2 S D)$ and the actual circumferential profile in six short-axis slices.

Quantitative coronary angiography. All patients underwent coronary angiography within 3 months of dobutamine stress testing. Coronary lesions were quantified using a previously described method from our centre [14].

Statistical analysis. Unless specified, data are presented as mean values \pm SD. The chi square test and Fisher exact test were used to compare differences between proportions. Student's $t$ test was used for analysis of continuous data. A $P$ value $<0.05$ was considered statistically significant.

\section{Results}

\section{Haemodynamic response}

Heart rate increased from $68 \pm 13$ to $132 \pm 17$ beats/min at peak stress $(P<0.0001)$ and systolic blood pressure from $133 \pm 21$ to $146 \pm 31 \mathrm{mmHg}(P<0.01)$. Atropine was administered in $37(44 \%)$ patients (mean dose $=0.6 \mathrm{mg}$ ). In 16 patients, the test was interrupted prematurely before reaching the maximal dose or the target heart rate. Reasons for premature termination of the test were angina in ten patients, ST-segment depression in three patients, hypotension in one patient and tachyarrhythmia in two patients. ST-segment depression occurred in 32 (38\%). Thirty-seven patients (44\%) developed typical angina during the test (symptomatic ischaemia group). The remaining 48 patients (56\%) without angina during the test constituted the silent ischaemia group.

\section{Demographic, haemodynamic and angiographic characteristics (Table 1)}

There was no significant difference between patients with and patients without angina with respect to age, gender, prevalence of previous myocardial infarction, diabetes mellitus, hypertension or smoking. A history of typical effort angina was encountered more frequently in patients with angina during the test. Peak heart rate was significantly lower in patients with angina, whereas peak rate pressure product was not significantly different in the two groups. ST-segment depression occurred in 20 of 37 patients with and in 12 of 48 patients without angina (54\% vs $25 \%, P<0.01$ ). Prevalence of multivessel disease, number of coronary arteries with significant stenosis, percentage diameter of the most severe stenosis and distribution of individual coronary artery stenoses were not significantly different between the two groups.

\section{MIBI SPET results (Table 2)}

There was no significant difference between patients with and patients without angina with respect to the number of myocardial segments with reversible defects, segments with perfusion defects on rest imaging, stress 
Table 1. Clinical and angiographic data of patients with coronary artery disease and reversible perfusion defects with and without angina during dobutamine stress testing

\begin{tabular}{lll}
\hline & Angina $(n=37)$ & Silent $(n=48)$ \\
\hline Age (years) & $60 \pm 10$ & $59 \pm 11$ \\
Male gender & $26(70 \%)$ & $35(73 \%)$ \\
Beta blocker therapy & $22(59 \%)$ & $22(46 \%)$ \\
History of angina pectoris & $16(43 \%)$ & $8(17 \%)^{*}$ \\
Previous myocardial infarction & $19(51 \%)$ & $28(58 \%)$ \\
Diabetes mellitus & $4(11 \%)$ & $6(13 \%)$ \\
Multivessel disease & $18(49 \%)$ & $22(46 \%)$ \\
Number of stenotic arteries & $1.7 \pm 0.8$ & $1.7 \pm 0.9$ \\
$\%$ diameter of most severe stenosis & $85 \% \pm 16 \%$ & $90 \pm 11 \%$ \\
$>90 \%$ diameter stenosis in $\geq 1$ artery & $28(75 \%)$ & $39(84 \%)$ \\
Peak heart rate (beats $/$ min) & $126 \pm 17$ & $137 \pm 19 *$ \\
Peak systolic blood pressure $\left(\mathrm{mmHg}^{*}\right)$ & $156 \pm 32$ & $138 \pm 31 \%$ \\
Peak rate pressure product & $19,633 \pm 4,287$ & $19,003 \pm 4,845$ \\
Peak dobutamine dose $\left(\mu \mathrm{g} \mathrm{kg}^{-1} \mathrm{~min}^{-1}\right)$ & $40 \pm 0$ & $39 \pm 4$ \\
\hline
\end{tabular}

$* P<0.01$
Table 2. Scintigraphic data of patients with coronary artery disease and reversible perfusion defects with and without angina during dobutamine stress testing

\begin{tabular}{lcc}
\hline & Angina $(n=37)$ & Silent $(n=48)$ \\
\hline Stress score & $7.1 \pm 3.1$ & $7.8 \pm 3.2$ \\
Rest score & $3.5 \pm 2.0$ & $4.0 \pm 2.3$ \\
Ischaemic score & $3.2 \pm 1.6$ & $3.9 \pm 2.3$ \\
Number of reversible defects & $1.6 \pm 0.8$ & $1.9 \pm 0.9$ \\
Number of fixed defects & $1.2 \pm 1.0$ & $1.2 \pm 1.1$ \\
$\quad$ on rest imaging & & \\
Quantitative stress defect & $1,426 \pm 1737$ & $1,251 \pm 1354$ \\
Quantitative rest defect & $1,063 \pm 1498$ & $825 \pm 965$ \\
Quantitative ischaemic defect & $472 \pm 630$ & $458 \pm 671$ \\
\hline
\end{tabular}

Table 3. Distribution of reversible perfusion defects in the six major left ventricular segments in patients with and patients without angina during dobutamine stress testing

\begin{tabular}{lrr}
\hline & Angina $(n=37)$ & Silent $(n=48)$ \\
\hline Anterior & $10(27 \%)$ & $15(31 \%)$ \\
Septal anterior & $8(22 \%)$ & $13(27 \%)$ \\
Septal posterior & $8(22 \%)$ & $11(23 \%)$ \\
Inferoposterior & $22(59 \%)$ & $28(58 \%)$ \\
Lateral & $5(14 \%)$ & $8(17 \%)$ \\
Apex & $6(16 \%)$ & $15(31 \%)$ \\
\hline
\end{tabular}

Values are expressed as number and percentage (\%) of patients with reversible perfusion defects in the specified region

perfusion defect score, rest score or ischaemic score by both visual and quantitative analysis. Exclusion of patients in whom the test was interrupted prematurely did not alter the comparable extent and severity of underperfusion with or without angina. The regional distribution of reversible defects was not different in the two groups (Table 3).
The perfusion scan of a patient with left anterior descending and right coronary artery stenosis and a reversible perfusion defect on dobutamine MIBI scintigraphy without angina or ST-segment depression during the test is shown in Fig. 1.

\section{Patients with ST-segment depression}

There was no significant difference between patients with and patients without ST-segment depression with respect to total number of reversible defects $(1.8 \pm 1.0 \mathrm{vs}$ $1.7 \pm 0.9$ ) or quantitative ischaemic score (Table 4). Reversible perfusion defects without angina or ST-segment depression occurred in 36 patients $(42 \%)$, whereas a combination of angina and ST-segment depression occurred in 20 patients $(23 \%)$. The quantitative ischaemic score was not different in the groups with various combinations of angina and ST-segment depression (Table 4).

\section{Extent and severity of ischaemia in single-vessel versus multivessel disease}

Patients with multivessel disease $(n=40)$ had a significantly higher number of reversible perfusion defects (2.1 \pm 1.2 vs $1.1 \pm 0.8, P<0.01)$, a significantly higher visual ischaemic score $(4.7 \pm 2.5$ vs $2.6 \pm 1.9, P<0.01)$ and a significantly higher quantitative ischaemic score $(610 \pm 762$ vs $310 \pm 411, P<0.05)$ than the 45 patients with single-vessel disease (Fig. 2).

\section{Discussion}

Evaluation of the extent and severity of reversible perfusion defects during stress testing is important for prognostic stratification of patients with coronary artery dis- 

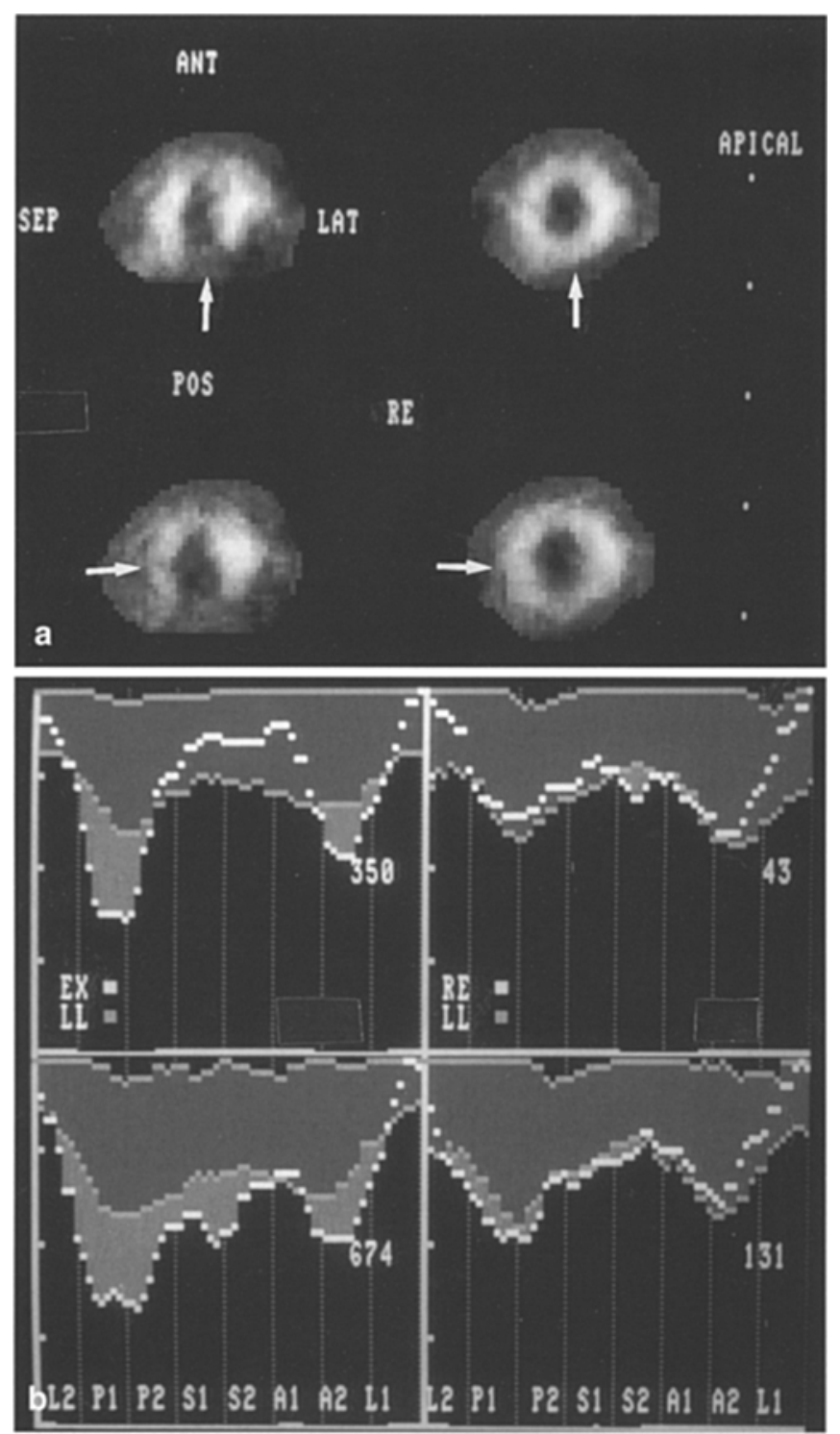

Fig. 1. a Dobutamine stress (left) and rest (right) MIBI perfusion scintigraphic images of a 55-year-old male with significant stenosis of the left anterior descending and right coronary arteries, from the apical short-axis level (the uppermost images are more apical). On the dobutamine stress images a large perfusion defect is observed in the posteroinferior wall (vertical arrows), and a small defect in the septum (horizontal arrows); these defects were shown to be reversible on the rest images. b Corresponding circumferential profile analysis. The patient had no symptoms or electrocardiographic changes during the test. ANT/A, Anterior; $S E P / S$, septum; $P O S / P$, posterior; $L A T / L$, lateral. $1-2$ is a clockwise division of the segments in the short-axis slices. $E X$, Stress; $R E$, rest; $L L$, lower limit

ease $[11,12]$. In our study, the additional value of angina and/or ST-segment depression in patients with coronary artery disease and dobutamine-induced ischaemia manifested as reversible perfusion defects on MIBI SPET was evaluated. Our finding of a higher number of reversible perfusion defects and a higher ischaemic score in patients with multivessel versus single-vessel disease vali-
Table 4. Quantitative ischaemic perfusion defect score in patients with different combinations of angina and ST-segment depression during dobutamine stress testing

\begin{tabular}{lll}
\hline & Yes & No \\
\hline ST depression & $508 \pm 680$ & $430 \pm 479$ \\
& $(32 \mathrm{pts})$ & $(53 \mathrm{pts})$ \\
Combined ST depression & $441 \pm 614$ & $465 \pm 679$ \\
$\quad$ and angina & $(20 \mathrm{pts})$ & $(65 \mathrm{pts})$ \\
ST depression & $534 \pm 699$ & $402 \pm 571$ \\
$\quad$ and/or angina & $(49 \mathrm{pts})$ & $(36 \mathrm{pts})$ \\
\hline
\end{tabular}

pts, Patients

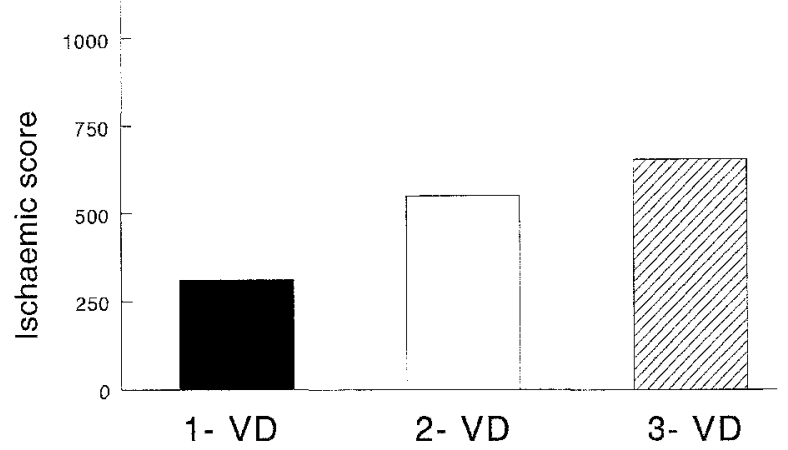

Fig. 2. Ischaemic perfusion defect score derived by quantitative analysis of the circumferential profile in patients with single-, two- and three-vessel disease $(V D)$, showing a positive correlation between the defect extent and severity and number of stenotic coronary arteries

dates the use of perfusion scintigraphy in the assessment of the extent of myocardial ischaemia.

Our results show that in patients with significant coronary artery disease and myocardial ischaemia detected by dobutamine perfusion scintigraphy, the extent and severity of coronary artery disease and reversible underperfusion do not differ according to whether angina is or is not present during the test. Parameters of reversible underperfusion were also similar in patients who had both angina and ST-segment depression and in patients without this combination. Apart from a higher prevalence of a history of typical angina in symptomatic patients during the test, clinical characteristics were not different in patients with and patients without angina during the dobutamine stress test.

\section{Comparison with previous studies}

To our knowledge, this is the first study in which the extent and severity of underperfusion in silent and symptomatic ischaemia during dobutamine stress testing have been evaluated. Discordant results have been published on the functional significance of silent versus symptomatic ischaemia during exercise stress testing [15-20]. Re- 
versible exercise-thallium defects were reported to be more extensive and severe in patients with compared to those without angina in the studies of Klein et al. [15] and Travin et al. [16], while others failed to demonstrate such a difference [17-20]. Klein et al. [15] concluded that the induction of pain is associated with substantially more functional abnormalities when patients with a broad spectrum of coronary artery disease are evaluated. They indicated that chest pain tends to lose its apparent value when its analysis is restricted to a coronary artery disease population with a greater pre-test likelihood of manifesting ischaemia.

\section{Studies of left ventricular function}

Various studies have compared the amount of abnormally contracting myocardium in silent and painful ischaemia during exercise stress testing using radionuclide ventriculography [21-23] or echocardiography [24-26]. Iskandrian and Hakki [21] and recently Nihoyannopolos et al. [26] reported that angina correlated with more severe deterioration of regional function. Other studies have demonstrated a comparable segmental and global exercise-induced left ventricular dysfunction in silent and symptomatic ischaemia evaluated by exercise radionuclide ventriculography $[22,23]$ or echocardiography $[24,25]$. We have recently shown that in patients with coronary artery disease, the extent and severity of dobutamine-induced left ventricular dysfunction assessed by echocardiography do not differ in patients with and patients without angina [27]. The results of this scintigraphic study confirm our previous findings. Although stress-induced wall motion abnormalities are highly specific for myocardial ischaemia, this study offers the following complementary advantages: (1) the quantitative assessment of perfusion compared to the visual semiquantitative echocardiographic assessment of wall motion; (2) the ability of perfusion scintigraphy to detect ischaemia in akinetic segments; (3) the less operator-dependent characteristics of the perfusion imaging technique; (4) the higher sensitivity of perfusion scintigraphy as compared with echocardiography at submaximal stress [28].

\section{Haemodynamic and electrical response}

Our results demonstrate a slightly lower peak heart rate in patients with angina and a comparable peak rate-pressure product. This may be attributed to early interruption of the test in 18 patients because of angina. However, exclusion of patients in whom the test was terminated prematurely did not alter the comparable parameters of underperfusion in patients with and patients without angina. The lower peak heart rate in patients with angina is consistent with previous reports on exercise $[15,20]$ and dobutamine stress testing [27]. ST-segment depression occurred more frequently in the symptomatic group. A higher prevalence of electrically silent ischaemia in asymptomatic patients has been reported during dobutamine [27] and exercise stress testing as well [17, 20, 25], which may suggest a common pathway for both the electrocardiographic and the pain response to ischaemic stimulus [20].

\section{$S T$-segment depression and the amount of ischaemia}

In this study, the extent and severity of reversible underperfusion during dobutamine stress testing did not differ in patients with and patients without ST-segment depression. We have previously reported a similar ischaemic wall motion score with or without ST-segment depression during dobutamine stress testing, and a higher number of ischaemic segments with normal baseline contraction in patients with ST-segment depression. However, in the present study we failed to identify a corresponding difference in number of segments with a completely reversible defect in patients with and patients without ST-segment depression. This contradiction may be explained by the fact that a partially reversible defect may represent ischaemia in the absence of baseline wall motion abnormalities. Additionally, in patients with myocardial infarction and stress-induced ST-segment elevation, concomitant ST-segment depression may represent reciprocal changes without true ischaemia. Hecht et al. [20] and Mahmarian et al. [19] reported that in patients with coronary artery disease, positive and negative exercise electrocardiographic findings were associated with a similar amount of ischaemia on exercise thallium scintigraphy. Conversely, Hecht et al. [25] concluded that exercise-induced STsegment depression is the single most significant variable in relation to the amount of ischaemic myocardium assessed by exercise echocardiography.

\section{Limitations of the study}

We assessed myocardial ischaemia on basis of reversible perfusion defects, which may represent flow malperfusion as well as true ischaemia. The detection of reversible perfusion defects in dyssynergic segments may represent a clinical challenge. Another limitation of the study is that most of the patients were receiving anti-anginal medication which may modify symptoms and signs of ischaemia. We have previously shown that the adminstration of atropine enhances the detection of myocardial ischaemia during dobutamine stress testing, especially in patients receiving beta blockers [29]. Furthermore, the percentage of patients receiving medications was not different in the two groups. Finally, STsegment depression in patients with myocardial infarction may represent reciprocal changes without ischaemia. Despite this limitation, exercise-induced ST-segment depression after myocardial infarction has general- 
ly been considered as a marker of a positive test associated with an adverse outcome [30].

\section{Conclusions}

In patients with coronary artery disease and ischaemia manifested as transient perfusion defects on dobutamine MIBI SPET imaging, the extent and severity of coronary artery disease and reversible underperfusion were comparable in patients with and patients without angina during the test. Patients with symptomatic ischaemia had a higher prevalence of typical effort angina before the test and a higher prevalence of ST-segment depression during the test. The amount of ischaemic myocardium was similar in patients with and patients without ST-segment depression. The absence of angina and/or ST-segment depression during stress testing of patients with anatomically and functionally significant coronary artery disease was not an indicator of less severe ischaemia.

Acknowledgements. A. Elhendy is supported by the Department of Cardiology, Cairo University Hospital, Cairo, Egypt. M.L. Geleijnse is supported by the Dutch Heart Foundation (grant NHS 94.135).

\section{References}

1. Salustri A, Fioretti PM, Pozzoli MMA, McNeill AJ, Roelandt JRTC. Dobutamine stress echocardiography: its role in the diagnosis of coronary artery disease. Eur Heart $J$ 1992; 13: $70-77$.

2. Mazeika PK, Nadazdin A, Oakley CM. Prognostic value of dobutamine echocardiography in patients with high pretest likelihood of coronary artery disease. Am J Cardiol 1993; 71: 33-39.

3. Marwick T, Willemart B, D'hondt AM, et al. Selection of the optimal nonexercise stress for the evaluation of ischaemic regional myocardial dysfunction and malperfusion: comparison of dobutamine and adenosine using echocardiography and $99 \mathrm{~m}$ Tc-MIBI single photon emission computed tomography. Circulation 1993; 87: 345-354.

4. Mairesse GH, Marwick TH, Vanoverschelde JJ, et al. How accurate is dobutamine stress electrocardiography for detection of coronary artery disease? Comparison with two-dimensional echocardiography and technetium-99m methoxyl isobutyle isonitrile (MIBI) perfusion scintigraphy. $J$ Am Coll Cardiol 1994; 24: 920-927.

5. Forster T, McNeill AJ, Salustri A, et al. Simultaneous dobutamine stress echocardiography and 99-m technetium isonitrile single photon emission computed tomography in patients with suspected coronary artery disease. I Am Coll Cardiol 1993; 21: $1591-1596$.

6. Günalp B, Dokumaci B, Uyan C, et al. Value of dobutamine technetium-99m-sestamibi SPET and echocardiography in detection of coronary artery disease compared with coronary angiography. I Nucl Med 1993; 34: 889-894.

7. Voth E, Baer FM, Theissen P, Schneider CA, Sechtem U, Schicha H. Dobutamine ${ }^{99 \mathrm{~m} T c-M I B I}$ single-photon emission tomography: non-exercise-dependent detection of haemodynam- ically significant coronary artery stenoses. Eur $J$ Nucl Med 1994; $21: 537-544$.

8. Hays JT, Mahmarian JJ, Cochran AJ, Verani MS. Dobutamine thallium-201 tomography for evaluating patients with suspected coronary artery disease unable to undergo exercise or vasodilator pharmacologic stress testing. I Am Coll Cardiol 1993; 21: 1583-1590.

9. Ruffolo RR. The pharmacology of dobutamine. Am J Med Soc 1987; 294: 244-248.

10. Warltier DC, Zyvoloski M, Gross GJ, Hardman HF, Brooks HL. Redistribution of myocardial blood flow distal to a dynamic coronary arterial stenosis by sympathomimetic amines: comparison of dopamine, dobutamine and isoproterenol. Am J Cardiol 1981; 48: 269-279.

11. Machecourt J, Longere P, Fagret D, Vanzetto G, Wolf JE, Polidori C. Prognostic value of thallium-201 single-photon emission computed tomographic myocardial perfusion imaging according to extent of myocardial defect. Study in 1,926 patients with follow-up at 33 months. $J$ Am Coll Cardiol 1994; 23: 1096-1106.

12. Travin MI, Boucher CA, Newell JB, LaRaia PJ, Flores AR, Eagle KA. Variables associated with a poor prognosis in patients with an ischaemic thallium-201 exercise test. Am Heart $J$ 1993; 125: 335-344.

13. Elhendy A, Geleijnse ML, Roelandt JRTC, et al. Evaluation by quantitative $99 \mathrm{~m}$-technetium MIBI SPET and echocardiography of myocardial perfusion and wall motion abnormalities in patients with dobutamine-induced ST-segment elevation. Am J Cardiol 1995; 76: 441-448.

14. Baptista J, Arnese M, Roelandt JRTC, et al. Quantitative coronary angiography in the estimation of the functional significance of coronary stenosis: correlation with dobutamine-atropine stress test. J Am Coll Cardiol 1994; 23: 1434-1439.

15. Klein J, Chao SY, Berman DS, Rozanski A. Is silent myocardial ischaemia really as severe as symptomatic ischaemia? The analytic effect of patient selection biases. Circulation 1994; 89: 1958-1966.

16. Travin MI, Flores AR, Boucher CA, Newell JB, LaRaia PJ. Silent versus symptomatic ischaemia during a thallium-201 exercise test. Am J Cardiol 1991; 68: 1600-1608.

17. Gasperetti CM, Burwell LR, Beller GA. Prevalence and variables associated with silent myocardial ischaemia on exercise thallium-201 stress testing. I Am Coll Cardiol 1990; 16: 115-123.

18. Amanullah AM, Lindvall K. Prevalence and significance of transient-predominantly asymptomatic-myocardial ischaemia on Holter monitoring in unstable angina pectoris, and correlation with exercise test and thallium-201 myocardial perfusion imaging. Am J Cardiol 1993; 72: 144-148.

19. Mahmarian JJ, Pratt CM, Cocaonugher MK, Verani MS. Altered myocardial perfusion in patients with angina pectoris or silent ischaemia during exercise as assessed by quantitative thallium-201 single photon emission computed tomography. Circulation 1990; 82: 1305-1315.

20. Hecht HS, Shaw RE, Bruce T, Mylder RK. Silent ischaemia; evaluation by exercise and redistribution tomographic thallium 201 myocardial imaging. J Am Coll Cardiol 1989; 14: 895-900.

21. Iskandrian AS, Hakki AH. Left ventricular function in patients with coronary heart disease in the presence or absence of angina pectoris during exercise radionuclide ventriculography. Am J Cardiol 1983; 53: 1239-1243.

22. Williams KA, Sherwood DF, Fisher KM. The frequency of asymptomatic and electrically silent exercise-induced regional 
myocardial ischaemia during first-pass radionuclide angiography with upright bicycle ergometry. J Nucl Med 1992; 33: 359-364.

23. Vassiliadis IV, Machac J, O'Hara M, Sezhiyan T, Horowitz SF. Exercise-induced myocardial dysfunction in patients with coronary artery disease with and without angina. Am Heart $J$ 1991; 121: 1403-1408.

24. Marwick TH, Nemec JJ, Torelli J, Salcedo EE, Stewart WJ, Extent and severity of abnormal left ventricular wall motion detected by exercise echocardiography during painful and silent ischaemia. Am J Cardiol 1992; 69: 1483-1484.

25. Hecht HS, DeBord L, Stomayor N, Shaw R, Ryan C. Truly silent ischaemia and the relationship of chest pain and ST segment changes to the amount of ischaemic myocardium: evaluation by supine bicycle stress echocardiography. J Am Coll Cardiol 1994; 23: 369-376.

26. Nihoyannopolos J, Marsonis A, Joshi J, Athanassopoulos G, Oakley C. Magnitude of myocardial dysfunction is greater in painful than in painless myocardial ischaemia: an exercise echocardiographic study. $J$ Am Coll Cardiol 1995; 25: 1507-1512.

27. Elhendy A, Gelijnse ML, Roelandt JRTC, Cornel JH, Domburg RT, Fioretti PM. Stress-induced left ventricular dysfunction in silent and symptomatic myocardial ischaemia during dobutamine stress test. Am J Cardiol 1995; 75: 1112-1115.

28. Elhendy A, Geleijnse ML, Roelandt JRTC, et al. Dobutamineinduced hypoperfusion without transient wall motion abnormalities. Less severe ischaemia or less severe stress? $J \mathrm{Am}$ Coll Cardiol 1996; 27: 323-329.

29. Fioretti PM, Poldermans D, Salustri A, et al. Atropine increases the accuracy of dobutamine stress echocardiography in patients taking beta-blockers. Eur Heart $J$ 1994; 15: 355-360.

30. Starling MR, Crawford MH, Kennedy GT, O'Rourke RA. Exercise testing early after myocardial infarction: predictive value for subsequent unstable angina and death. Am $J$ Cardiol 1980; 46: 909-914. 